Check for updates

Cite this: RSC Adv., 2018, 8, 40968

Received 7th November 2018 Accepted 30th November 2018

DOI: 10.1039/c8ra09214a

rsc.li/rsc-advances

\title{
A copper(II)-catalyzed annulative formylation of 0 - alkynylanilines with DMF: a single-step strategy for 3-formyl indoles $\uparrow$
}

\author{
Balaji Ganesan, (ID a Gopal Chandru Senadi, (D) ab Bing-Chun Guo, a Min-Yuan Hung ${ }^{c}$ \\ Balaji Ganesan, (D) a Gopal Chandru Senadi, (D) ab Bing-Chun Guo, ${ }^{a}$ Min-Yuan Hung ${ }^{c}$
and Wei-Yu Lin (D) *a
}

In this paper, a copper(II)-catalyzed reaction of $O$-alkynylanilines with dimethylformamide (DMF) in the presence of oxygen has been developed for synthesizing multisubstituted 3-formyl indole scaffolds. This one-pot reaction proceeds through a cascade 5 -endo-dig cyclization followed by formylation to construct 1,2-disubstituted 3-formyl indoles. The key aspects of this synthesis method are the broad substrate scope (with 38 examples), and well tolerating various functional groups. In addition, a detailed mechanism has been proposed, where DMF may serve as a carbon source for the in situ C3 formylation of the obtained indole derivatives.
\end{abstract}

\section{Introduction}

2,3-Disubstituted and 1,2,3-multi-substituted indoles are widely available in various alkaloids and natural products possessing potential biological activities. Several essential examples include indometacin, pyrazolybisindoles and substituted tryptamine derivatives, which exhibit significant anticancer activities (Scheme 1). ${ }^{1}$ Among these crucial molecules, intermediates with a formyl functional group at the $\mathrm{C} 3$ position can serve as a primary building block to construct substituted indoles through their broad and specific reactivity for various chemical transformations. Therefore, 1,2,3-tri-substituted indole preparation has received considerable interest in previous decades.

According to a literature survey, several pioneering methods have been reported for the construction of 1,2 di-substituted 3formyl indoles through two-step reactions. The first step involves the use of the easily accessible starting materials of $o$ alknylaniline derivatives and is mediated by transition metals $\left(\mathrm{Pt},{ }^{2} \mathrm{Pd},{ }^{3} \mathrm{Ag},{ }^{4} \mathrm{Au},{ }^{5} \mathrm{Ir},{ }^{6} \mathrm{In},{ }^{7} \mathrm{Fe},{ }^{8}\right.$ and $\left.\mathrm{Cu}^{9}\right)$, the molecular halogen ${ }^{10}$ catalyzed annulation of $o$-alknylaniline derivatives, or free radical assisted indole construction through either $\mathrm{C}-\mathrm{C}$ or $\mathrm{C}-\mathrm{N}$ bond-forming reactions. ${ }^{11}$ The second step involves direct formylation by an existing indole using the Vilsmeier-Haack

${ }^{a}$ Department of Medicinal and Applied Chemistry, Kaohsiung Medical University, No. 100 Shi-chuan, 1st Road, Kaohsiung 807, Taiwan. E-mail: wylin@kmu.edu.tw

${ }^{b}$ Department of Chemistry, SRM Institute of Science and Technology, Kattankulathur, Chennai-603203, India

${ }^{c}$ Center for Research Resources and Development, Kaohsiung Medical University, No. 100 Shi-chuan, 1st Road, Kaohsiung 807, Taiwan

$\dagger$ Electronic supplementary information (ESI) available. CCDC 1876301 (2a). For ESI and crystallographic data in CIF or other electronic format see DOI: 10.1039/c8ra09214a reaction, ${ }^{12}$ or other methods ${ }^{13}$ (Scheme 2, eqn (1)). Tsui and coworkers $^{\mathbf{1 4}}$ recently reported an elegant method for synthesizing 2-(trifluoromethyl)indoles from $N$-mesylated-2alkynylanilines through domino cyclization and formylation by using TMEDA as a carbon synthon (Scheme 2, eqn (2)). ${ }^{\mathbf{1 4}}$ Although these methods are potentially useful, some have certain limitations, such as desulfonylation, postfunctionalization is necessary for the $\mathrm{N}$-substitution of the indole derivatives, expensive metal-catalysts ${ }^{2-5}$ and strong acidic conditions. ${ }^{12}$ Herein, we wish to report a complementary approach by employing $o$-phenylethynyl $N$-substituted aniline $(\mathbf{1}, \mathbf{3}$, and 5) as a starting material for the one-pot domino synthesis of multisubstituted-3-formyl indole (2, 4, and 6) using DMF in the presence of oxygen (Scheme 2, eqn (3)). Moreover, detailed mechanistic studies of the $\mathrm{Cu}(\mathrm{II})$ and $\mathrm{O}_{2}$-mediated formylation were conducted.

\section{Results and discussion}

To optimize reaction parameters, preliminary screening was conducted using o-phenylethynyl aniline $\mathbf{1 a}$ as a model substrate (Table 1 ). The reaction was initially carried out using

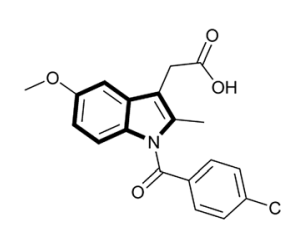

Indometaicn Anti-inflammatory drug

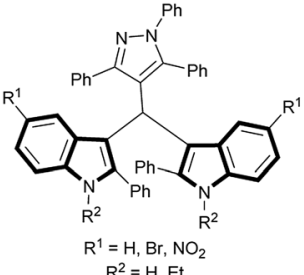

Pyrazolybisindoles Antifungal activity

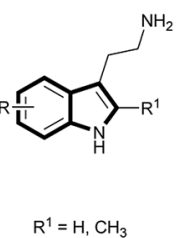

Tryptamine derivatives
Marine alkaloids
Scheme 1 Biological importance of indole derivatives. 
Previous work:
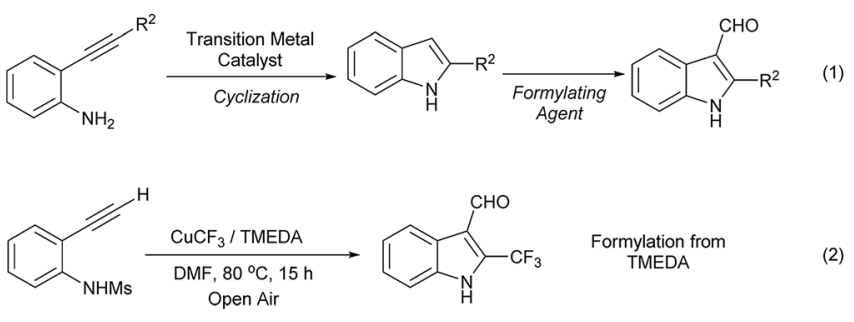

This work:

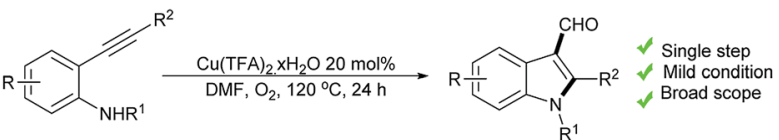

Scheme 2 Previous and this work on 3-formyl indoles.

1a in DMF $(0.25 \mathrm{M})$ with $20 \mathrm{~mol} \%$ of $\mathrm{Cu}(\mathrm{OAc})_{2} \cdot \mathrm{H}_{2} \mathrm{O}$ as a catalyst, and TFA as an additive (2.0 equiv.) under an $\mathrm{O}_{2}$ atmosphere at $120{ }^{\circ} \mathrm{C}$ for $24 \mathrm{~h}$. The desired product $2 \mathrm{a}$ was obtained in $31 \%$ yield (Table 1 , entry 1 ). To optimize the catalyst, TFA was added as an additive with various copper catalysts such as anhyd. $\mathrm{Cu}(\mathrm{OAc})_{2}, \mathrm{Cu}(\mathrm{OTf})_{2}, \mathrm{CuSO}_{4} \cdot \mathrm{H}_{2} \mathrm{O}, \mathrm{Cu}(\mathrm{I})$, and $\mathrm{Cu}$. The desired product $2 \mathrm{a}$ was obtained in $45 \%$ yield when $\mathrm{Cu}$ powder was used as a catalyst (Table 1, entries 2-6). The reaction yield did not improve when different Brønsted acids were used, including
TfOH and TsOH $\cdot \mathrm{H}_{2} \mathrm{O}$ additives (Table 1, entries 7-8). 2a was not obtained, when only $\mathrm{Cu}$ was added as a catalyst (Table 1 , entry 9). To our delighted, $\mathrm{Cu}(\mathrm{TFA})_{2} \cdot x \mathrm{H}_{2} \mathrm{O}$ was used as a catalyst instead of $\mathrm{Cu} / \mathrm{TFA}$, and the reaction yield increased to $52 \%$ (Table 1, entry 10). The reaction yield was reduced to $32 \%$ when the reaction was performed in air (Table 1, entry 11). Furthermore, no product was formed under a $\mathrm{N}_{2}$ atmosphere (Table 1, entry 12). Other oxidants such as DDQ, and AgOAc under the $\mathrm{N}_{2}$ atmosphere, resulted in low yield (Table 1, entries 13-14). These

Table 1 Optimization of the reaction conditions ${ }^{a}$

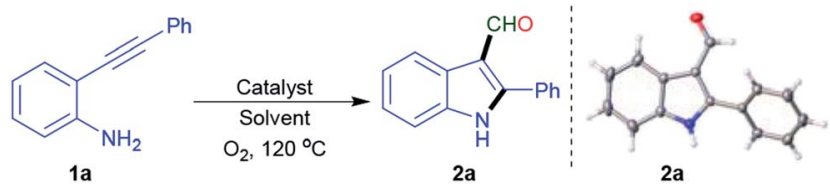

\begin{tabular}{|c|c|c|c|c|c|}
\hline Entry & Catalyst (20 mol\%) & Additive (2.0 equiv.) & Oxidant & Solvent/time (h) & Yield $^{b}(\%)$ \\
\hline 1 & $\mathrm{Cu}(\mathrm{OAc})_{2} \cdot \mathrm{H}_{2} \mathrm{O}$ & TFA & $\mathrm{O}_{2}$ & $\mathrm{DMF} / 20$ & 31 \\
\hline 2 & $\mathrm{Cu}(\mathrm{OAc})_{2}$ & TFA & $\mathrm{O}_{2}$ & $\mathrm{DMF} / 14$ & 37 \\
\hline 4 & $\mathrm{CuSO}_{4} \cdot \mathrm{H}_{2} \mathrm{O}$ & TFA & $\mathrm{O}_{2}$ & $\mathrm{DMF} / 25$ & 27 \\
\hline 5 & CuI & TFA & $\mathrm{O}_{2}$ & $\mathrm{DMF} / 22$ & 27 \\
\hline 6 & $\mathrm{Cu}$ & TFA & $\mathrm{O}_{2}$ & $\mathrm{DMF} / 20$ & 45 \\
\hline 9 & $\mathrm{Cu}$ & - & $\mathrm{O}_{2}$ & $\mathrm{DMF} / 20$ & N.R \\
\hline 10 & $\mathrm{Cu}(\mathrm{TFA})_{2} \cdot x \mathrm{H}_{2} \mathrm{O}$ & - & $\mathrm{O}_{2}$ & $\mathrm{DMF} / 24$ & 52 \\
\hline $11^{c}$ & $\mathrm{Cu}(\mathrm{TFA})_{2} \cdot x \mathrm{H}_{2} \mathrm{O}$ & - & Open air & $\mathrm{DMF} / 24$ & 32 \\
\hline $12^{d}$ & $\mathrm{Cu}(\mathrm{TFA})_{2} \cdot x \mathrm{H}_{2} \mathrm{O}$ & - & - & $\mathrm{DMF} / 24$ & N.R \\
\hline 13 & $\mathrm{Cu}(\mathrm{TFA})_{2} \cdot x \mathrm{H}_{2} \mathrm{O}$ & - & DDQ & $\mathrm{DMF} / 24$ & 16 \\
\hline 14 & $\mathrm{Cu}(\mathrm{TFA})_{2} \cdot x \mathrm{H}_{2} \mathrm{O}$ & - & AgOAc & $\mathrm{DMF} / 24$ & 11 \\
\hline $19^{f}$ & $\mathrm{Cu}(\mathrm{TFA})_{2} \cdot x \mathrm{H}_{2} \mathrm{O}$ & - & $\mathrm{O}_{2}$ & $\mathrm{DMF} / 24$ & 30 \\
\hline $20^{g}$ & $\mathrm{Cu}(\mathrm{TFA})_{2} \cdot x \mathrm{H}_{2} \mathrm{O}$ & - & $\mathrm{O}_{2}$ & $\mathrm{DMF} / 24$ & 54 \\
\hline
\end{tabular}

${ }^{a}$ Reaction conditions 1a (1.0 equiv.), catalyst $(20 \mathrm{~mol} \%)$, solvent $(3.0 \mathrm{~mL}), \mathrm{O}_{2}$ balloon, $120{ }^{\circ} \mathrm{C}, 24 \mathrm{~h}$ at indicated time unless otherwise noted. ${ }^{b}$ Isolated yield. ${ }^{c}$ Reaction was performed under open air. ${ }^{d}$ Reaction was performed under nitrogen atmosphere. ${ }^{e} 5 \mathrm{~mol} \%$ of $\mathrm{Cu}(\mathrm{TFA})_{2} \cdot x \mathrm{H}_{2} \mathrm{O}$ was used. ${ }^{f} 10 \mathrm{~mol} \%$ of $\mathrm{Cu}(\mathrm{TFA})_{2} \cdot x \mathrm{H}_{2} \mathrm{O}$ was used. ${ }^{g}$ Another $20 \mathrm{~mol} \%$ of $\mathrm{Cu}(\mathrm{TFA})_{2} \cdot x \mathrm{H}_{2} \mathrm{O}$ was added after $12 \mathrm{~h}$. 


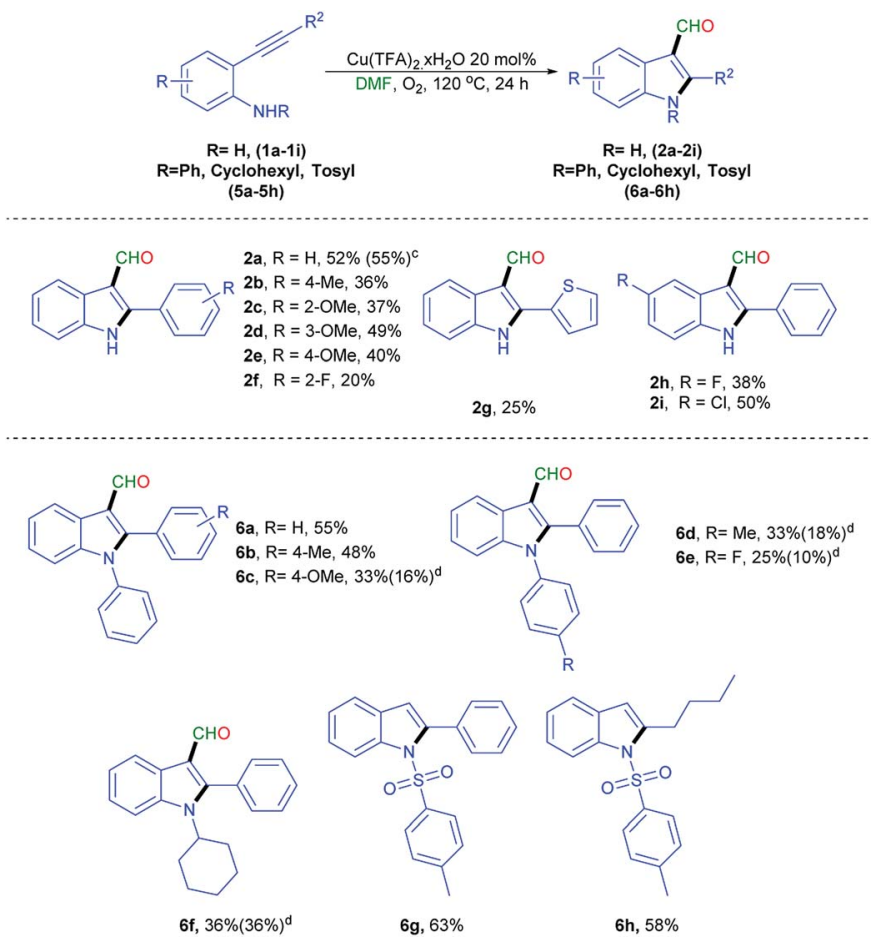

Scheme 3 Scope of 2-phenylethynyl aniline derivatives ${ }^{a, b}$. ${ }^{a}$ Reaction conditions: 1a $(0.3 \mathrm{mmol}), \mathrm{Cu}(\mathrm{TFA})_{2} \cdot \mathrm{xH}_{2} \mathrm{O}(20 \mathrm{~mol} \%), \mathrm{DMF}(3 \mathrm{~mL})$, $120{ }^{\circ} \mathrm{C}, 24 \mathrm{~h}, \mathrm{O}_{2} .{ }^{b}$ Isolated yield. ${ }^{c} 3.0 \mathrm{mmol}$ scale. ${ }^{d}$ Recovered yield of starting material.

results indicate that the oxygen supply is crucial for the reaction. The use of alternative solvents such as, dioxane, DMSO, and a binary solvent system (THF/DMF $1: 1)$ generated trace yield (Table 1, entries 15-17). When the catalyst was reduced to $5 \mathrm{~mol} \%$ or $10 \mathrm{~mol} \%$, the reaction yield was reduced (Table 1 , entries 18-19). The addition of another $20 \mathrm{~mol} \%$ of $\mathrm{Cu}(\mathrm{TFA})_{2}$ $\cdot x \mathrm{H}_{2} \mathrm{O}$ catalyst after $12 \mathrm{~h}$, did not substantially improve the reaction yield (Table 1 , entry 20 ).

With the optimized conditions (Table 1, entry 10), the scope of this reaction was studied using o-phenylethynyl aniline derivatives [(1a-1i) and $(\mathbf{5 a}-\mathbf{5 h})]$, and the reaction results are summarized in Scheme 3. To evaluate the reaction scope and probable substituent effects of $\mathrm{R}^{2}$, various functional groups including substituted phenyls, and the heterocyclic group were studied (Scheme 3, 1a-1g). Compared with 1a, substrates with electron-donating groups on the phenyl ring, such as 2-Me and 2 or 4-OMe were suitable for this reaction, generating the corresponding products $2 \mathbf{b}, 2 \mathbf{c}$ and $2 \mathbf{e}$ in moderate yield. A substrate with electron-withdrawing groups, such as 2-F (1f) gave $2 \mathbf{f}$ in lower yield. When the substituent group was thiophene (19), the desired was obtained in a low yield of $25 \%(2 \mathrm{~g})$. The substituent on the aryl ring (R) was subsequently studied (Scheme 3, 1h-1i). Electron-withdrawing groups, including 4-F (11), and 4-Cl (1 $\mathbf{m})$ generated the corresponding products $2 \mathbf{l}$ and $2 \mathbf{m}$ in $38 \%$ and $50 \%$ yield, respectively. A scale up experiment could be performed in a $3 \mathrm{mmol}$ scale of $1 \mathrm{a}$, to obtain $2 \mathrm{a}$ in $55 \%$ yield, indicating the efficacy and scalability of the reaction. The structure of $2 \mathrm{a}$ was validated through X-ray crystallography analysis, and the data was presented in ESI. $\dagger^{18}$ The scope of the $N$-phenyl-2-phenylethynyl aniline derivatives $(\mathbf{5 a}-\mathbf{5 h})$ were explored and the resulting data are shown in Scheme 3 . Electron-donating groups at the alkynyl position, exhibiting the desired product $(\mathbf{6 a - 6 \mathbf { c }})$ in $33-55 \%$ yields. $4-\mathrm{Me}(\mathbf{5 d})$, and $4-\mathrm{F}$ (5e) groups on the $N$-phenyl were formed smoothly, with 10$18 \%$ recovery of starting materials. A cyclohexyl group (5f) present on a nitrogen atom gave the desired product (6f). Surprisingly, when $N$-tosylate-2-phenylethynyl aniline derivatives ( $\mathbf{5} \mathbf{g}$ and $\mathbf{5 h}$ ) used as substrates, only led to the formation of indole $^{14}$ (Scheme 5, 6g, 6h).

With the successful outcome of 2,3 di-substituted indole derivatives, this method was extended to synthesize of $1,2,3$ trisubstituted indole derivatives by using the $N$-benzylated 2 phenylethynyl aniline derivatives (3a-3u) under the optimized conditions (Scheme 4). When 3a was tested, the desired product 4a was obtained in $34 \%$ yield. Substituents at the $\mathrm{R}^{2}$ position with a phenyl ring having electron-donating groups, such as 2Me (3b), 4-Me (3c), 2-OMe (3d), and 4-OMe (3f) had appropriate reactivity. By contrast, the electron-withdrawing groups, including $3-\mathrm{Cl}(3 \mathbf{g}), 3-\mathrm{NO}_{2}(3 \mathbf{h})$, and $3-\mathrm{CF}_{3}(3 \mathbf{i})$, produced the corresponding products in moderate yields $(32-44 \%)$. Thiophene group (3j) smoothly proceeded in $60 \%$ yield. Aliphatic groups, such as hexyl (3k) and cyclopropane (3l), were examined, the desired products were obtained in $30 \%$ and $33 \%$ yields, respectively. The substitution of a phenyl ring bearing an

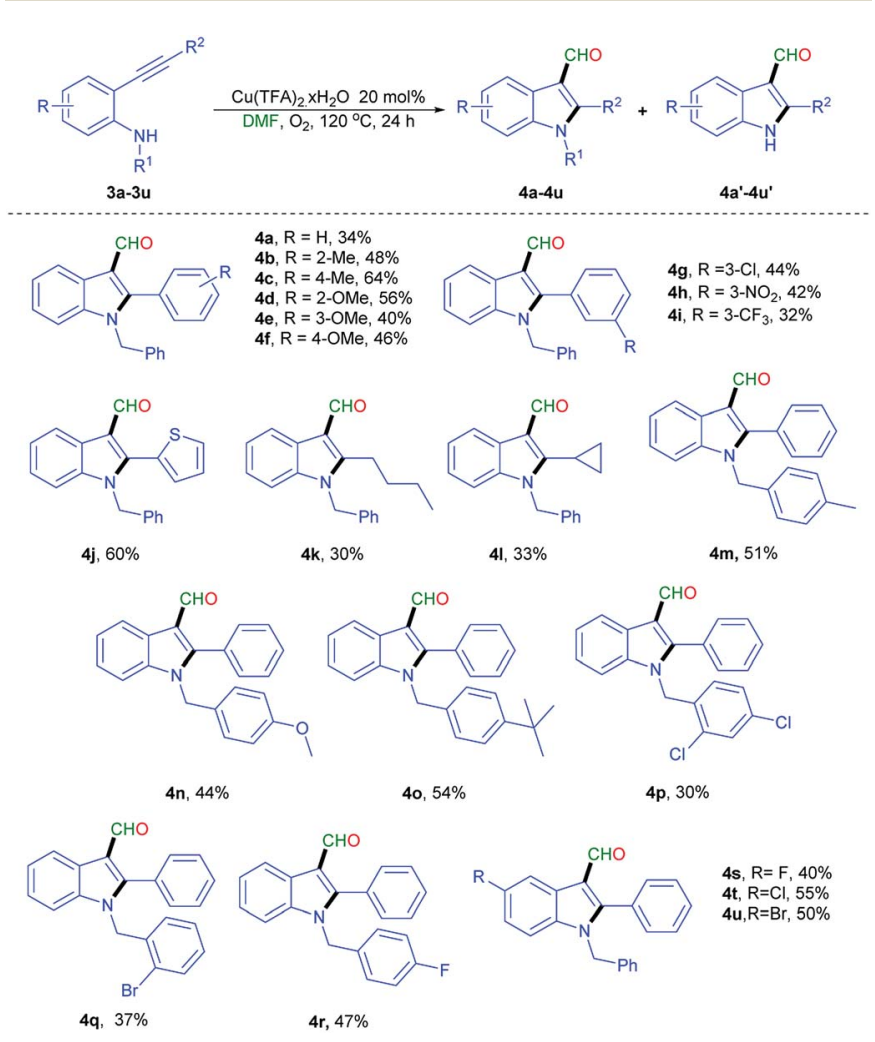

Scheme 4 Scope $\mathrm{N}$-benzylated-2-phenylethynyl aniline derivatives ${ }^{a, b, c}$. ${ }^{a}$ Reaction conditions: $3 a-3 v(0.3 \mathrm{mmol}), \mathrm{Cu}(\mathrm{TFA})_{2} \cdot \mathrm{xH}_{2} \mathrm{O}$ (20 mol\%), DMF (3 mL), $120{ }^{\circ} \mathrm{C}, 24 \mathrm{~h}, \mathrm{O}_{2} .{ }^{b}$ Isolated yield. ${ }^{c}$ Please see Table S1 in ESI† for isolated yield of $4 a^{\prime}-4 u^{\prime}$. 


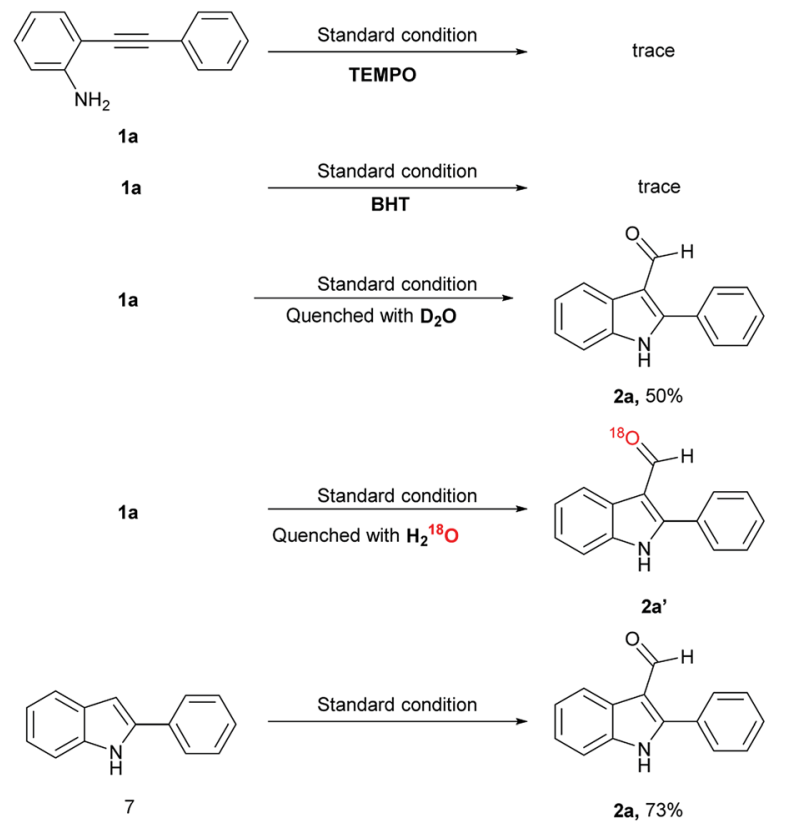

Scheme 5 Control experiments.

electron donating groups such as 4-Me (3m), 4-OMe (3n), and $t$ $\mathrm{Bu}(3 \mathrm{o})$, on $\mathrm{R}^{1}$ provided moderate yield (44-54\%). The presence of electron withdrawing groups (3p-3r) on a benzyl ring generated a similar moderate yield. An indole phenyl ring bearing with electron withdrawing groups such as $\mathrm{F}(3 \mathbf{s}), \mathrm{Cl}(3 \mathbf{t})$, and $\mathrm{Br}$ $(3 \mathbf{u})$ provided in good yield. During this reaction, the formation of debenzylation products was observed (ESI $\dagger$ ). This formation might be a side reaction of substrate with molecular oxygen under high temperature. ${ }^{\mathbf{1 4 , 1 5}}$

To understand the formation of the 3 -formyl indoles derivatives, several control experiments were performed (Scheme 5). Table 1 (vide supra) indicates that when oxygen was replaced by air or nitrogen, the reaction yield was reduced to $32 \%$ and $0 \%$, respectively (Table 1, entries 11 and 12). These results revealed that sufficient supply of oxygen is necessary for this reaction. When a 2.5 equivalent of common radical scavengers, including TEMPO or BHT was added, a trace amount $(<5 \%)$ of 2 a was detected through GC-MS and the starting material remained. The results suggested that this reaction may occur through a radical process (Scheme 5, eqn (1) and (2)). The addition of $\mathrm{D}_{2} \mathrm{O}$ after the completion of the reaction could not afford the deuterium-labeled aldehyde in 50\% yield (Scheme 5, eqn (3)). The addition of ${ }^{18} \mathrm{O}$-labeled water to the reaction mixture under a standard condition afforded $100 \%$ of ${ }^{18} \mathrm{O}$-labeling product $2 \mathrm{a}^{\prime}$ (Scheme 5, eqn (4), and ESI $\dagger$ ), where the oxygen atom of the formyl group is originated from water. The reaction with the 3$H$-indole substrate 7 generated 2a in good yield (73\%) under the standard condition (Scheme 5, eqn (5)). These results indicate that the product formation was through a pathway involving radical intermediates that utilized molecular oxygen as an oxidant.

The proposed mechanism is based on the control experiments and previous reports ${ }^{\mathbf{1 3 e}, \mathbf{1 4 , 1 6 , 1 7}}$ (Scheme 6). DMF was
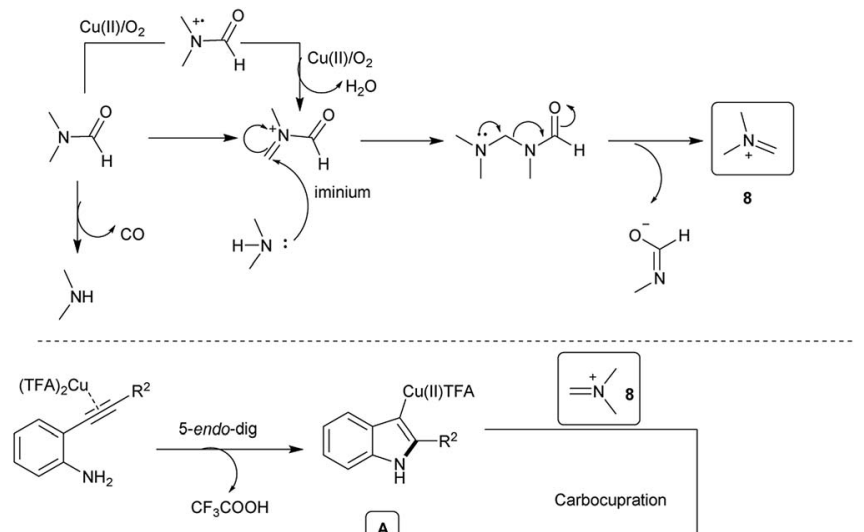

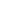
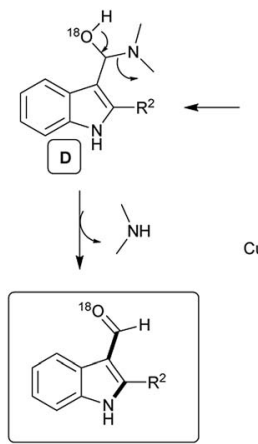

Scheme 6 Proposed mechanism.

activated by $\mathrm{Cu}(\mathrm{II})$ and oxygen to generate the iminium ion 8. ${ }^{13 e, 14,16}$ The simultaneous electrophilic activation of alkyne by $\mathrm{Cu}$ (II) and intramolecular 5-endo-dig cyclization generated the vinyl $\mathrm{Cu}$ (II) intermediate $\mathbf{A}^{\mathbf{1 4}}$ The carbocupration of the intermediate $\mathbf{A}$ and the reaction with an iminium ion led to formation of the $N-\mathrm{Cu}(\mathrm{II})$ intermediate $\mathbf{B}^{\mathbf{1 3 e , 1 4 , 1 6 , 1 7}}$ The $\beta$-hydride elimination of the $\mathbf{B}$ gave the primary iminium species $\mathbf{C}$ along with the catalytic regeneration of $\mathrm{Cu}(0)$ in the presence of oxygen. The nucleophilic addition of ${ }^{18} \mathrm{O}$-labeled water to the $\mathbf{C}$ generated the hemiketal intermediate D. Finally, the elimination of dimethylamine from the $\mathbf{D}$ generated the desired 3formyl indoles derivatives.

\section{Experimental}

Experimental procedure, ${ }^{11 a}$ crystallographic data and spectroscopic data of new starting materials and final products were given in ESI. $\dagger^{+18}$

In sealed tube, $\boldsymbol{o}$-alkynylaniline derivatives $(\mathbf{1 a - 1 i}, \mathbf{5 a}-\mathbf{5 h} \&$ 3a-3u) $(0.3 \mathrm{mmol})$ was taken in DMF $(3 \mathrm{~mL})$. To the stirred solution, $\mathrm{Cu}(\mathrm{TFA})_{2} \cdot x \mathrm{H}_{2} \mathrm{O}(20 \mathrm{~mol} \%)$ was added and allowed to stir under $\mathrm{O}_{2}$ source at $120{ }^{\circ} \mathrm{C}$, until the completion of starting material $(\sim 24 \mathrm{~h})$. The reaction mixture was quenched with ice cold water and extracted with ethyl acetate. Combined organic layer washed with brine, dried over $\mathrm{MgSO}_{4}$ and concentrated in vacuum. Then the crude material was purified by column chromatography using $20 \%$ ethyl acetate in hexane as eluent to afford the desired product $(\mathbf{2} \mathbf{a}-\mathbf{2} \mathbf{i}, \mathbf{6 a}-\mathbf{6 h} \& \mathbf{4 a}-\mathbf{4} \mathbf{u})$. 


\section{Conclusions}

In summary, in this paper, a new synthetic method was developed for the direct synthesis of 1,2-disubstituted 3-formyl indole or 2-substituted 3-formyl indole from the common starting materials of $o$-alkynylaniline through 5-endo-dig cyclization followed by an iminium ion attack at the $\mathrm{C} 3$ position. Compared with other methods, this one-pot reaction was using the inexpensive Cu-catalyst and DMF as a formyl carbon source, without any additives. This method can be used with a wide range of functional groups and the desired products can be obtain up to moderate yield. In the near future, this method can be adapted as a potential route for the direct synthesis of 3formyl indole. Further investigation of this reaction in continuous flow system are currently ongoing in our laboratories.

\section{Conflicts of interest}

There are no conflicts to declare.

\section{Acknowledgements}

The authors gratefully acknowledge funding from the Ministry of Science and Technology (MOST 106-2113-M-037-009-), Taiwan, and the Center for Research Resources and Development (CRRD) of Kaohsiung Medical University for Mass and $400 \mathrm{MHz}$ NMR analyses.

\section{Notes and references}

1 T. V. Sravanthi and S. L. Manju, Eur. J. Pharm. Sci., 2016, 91, 1-10.

2 (a) P. Rubio-Marques, M. A. Rivero-Crespo, A. Leyva-Perez and A. Corma, J. Am. Chem. Soc., 2015, 137, 11832-11837; (b) N. Chaisan, W. Kaewsri, C. Thongsornkleeb, J. Tummatorn and S. Ruchirawat, Tetrahedron Lett., 2018, 59, 675-680.

3 (a) C. Xu, V. K. Murugan and S. A. Pullarkat, Org. Biomol. Chem., 2012, 10, 3875-3881; (b) J. Kwon, J. Chung, S. Byun and B. M. Kim, Asian J. Org. Chem., 2016, 5, 470-476; (c) E. Tyrrell, L. Whiteman and N. Williams, Synthesis, 2009, 829-835.

4 (a) A. Arcadi, M. Chiarini, L. Del Vecchio, F. Marinelli and V. Michelet, Chem. Commun., 2016, 52, 1458-1461; (b) S. Karmakar, P. Das, D. Ray, S. Ghosh and S. K. Chattopadhyay, Org. Lett., 2016, 18, 5200-5203; (c) H. P. Sun, L. Xiao, W. Li, Q. Xie and L. M. Shao, Synthesis, 2017, 49, 4845-4852.

5 (a) E. Chong and S. A. Blum, J. Am. Chem. Soc., 2015, 137, 10144-10147; (b) J. E. Perea-Buceta, T. Wirtanen, O. V. Laukkanen, M. K. Makela, M. Nieger, M. Melchionna, N. Huittinen, J. A. Lopez-Sanchez and J. Helaja, Angew. Chem., Int. Ed., 2013, 52, 11835-11839; (c) S. Z. Liang, L. Hammond, B. Xu and G. B. Hammond, Adv. Synth. Catal., 2016, 358, 3313-3318; (d) O. S. Morozov, A. V. Lunchev, A. A. Bush, A. A. Tukov, A. F. Asachenko, V. N. Khrustalev, S. S. Zalesskiy, V. P. Ananikov and
M. S. Nechaev, Chem.-Eur. J., 2014, 20, 6162-6170; (e) K. C. Majumdar, S. Samanta and B. Chattopadhyay, Tetrahedron Lett., 2008, 49, 7213-7216.

6 (a) E. Kumaran and W. K. Leong, Tetrahedron Lett., 2014, 55, 5495-5498; (b) X. W. Li, A. R. Chianese, T. Vogel and R. H. Crabtree, Org. Lett., 2005, 7, 5437-5440.

7 (a) N. Sakai, K. Annaka, A. Fujita, A. Sato and T. Konakahara, J. Org. Chem., 2008, 73, 4160-4165; (b) N. Sakai, K. Annaka and T. Konakahara, Org. Lett., 2004, 6, 1527-1530.

8 V. Terrasson, J. Michaux, A. Gaucher, J. Wehbe, S. Marque, D. Prim and J. M. Campagne, Eur. J. Org. Chem., 2007, 5332-5335.

9 (a) Y. B. Ye, K. P. S. Cheung, L. S. He and G. C. Tsui, Org. Chem. Front., 2018, 5, 1511-1515; (b) H. F. Wang, Y. M. Li, L. L. Jiang, R. Zhang, K. Jin, D. F. Zhao and C. Y. Duan, Org. Biomol. Chem., 2011, 9, 4983-4986; (c) F. Liu and D. Ma, J. Org. Chem., 2007, 72(13), 4844-4850; (d) S. Cacchi, G. Fabrizi and L. M. Parisi, Org. Lett., 2003, 5(21), 38433846; (e) K. S. Kumar, B. Rajesham, M. S. Ramulu, B. Bhaskar, S. N. Dash, M. A. Ashfaq, R. Nagarapu, A. A. Khan, S. Lehtonen and M. Pal, RSC Adv., 2016, 6, 100487; (f) S. Cacchi, G. Fabrizi, L. M. Parisi and R. Bernini, Synlett, 2004, 2, 0287-0290; (g) G. A. Slough, V. Krchňák, P. Helquist and S. M. Canham, Org. Lett., 2004, 6(17), 2909-2912.

10 Y. Takeda, R. Kajihara, N. Kobayashi, K. Noguchi and A. Saito, Org. Lett., 2017, 19, 6744-6747.

11 (a) G. C. Senadi, J. Q. Wang, B. S. Gore and J. J. Wang, Adv. Synth. Catal., 2017, 359, 2747-2753; (b) G. C. Senadi, B. S. Gore, W. P. Hu and J. J. Wang, Org. Lett., 2016, 18, 2890-2893; (c) S. S. K. Boominathan, G. C. Senadi, J. K. Vandavasi, J. Y. F. Chen and J. J. Wang, Chem.-Eur. J., 2015, 21, 3193-3197; (d) G. C. Senadi, W. P. Hu, S. S. K. Boominathan and J. J. Wang, Adv. Synth. Catal., 2013, 355, 3679-3693.

12 (a) J. Qu, N. Kumar, M. Alamgir and D. S. Black, Tetrahedron Lett., 2009, 50, 5628-5630; (b) S. Naureen, F. Chaudhry, N. Asif, M. A. Munawar, M. Ashraf, F. H. Nasim, H. Arshad and M. A. Khan, Eur. J. Med. Chem., 2015, 102, 464-470; (c) M. Nyerges, A. Pinter, A. Viranyi, I. Bitter and L. Toke, Tetrahedron Lett., 2005, 46, 377-380.

13 (a) J. B. Chen, B. Liu, D. F. Liu, S. Liu and J. Cheng, Adv. Synth. Catal., 2012, 354, 2438-2442; (b) Z. P. Yin, Z. C. Wang and X. F. Wu, Org. Biomol. Chem., 2018, 16, 3707-3710; (c) Q. D. Wang, J. M. Yang, D. Fang, J. M. Ren and B. B. Zeng, Tetrahedron Lett., 2017, 58, 2877-2880; (d) Q. D. Wang, B. Zhou, J. M. Yang, D. Fang, J. M. Ren and B. B. Zeng, Synlett, 2017, 28, 2670-2674; (e) B. Zhang, B. Liu, J. B. Chen, J. H. Wang and M. C. Liu, Tetrahedron Lett., 2014, 55, 5618-5621; (f) H. Y. Fei, J. T. Yu, Y. Jiang, H. Guo and J. Cheng, Org. Biomol. Chem., 2013, 11, 70927095; $(g)$ X. Li, X. Y. Gu, Y. J. Li and P. X. Li, ACS Catal., 2014, 4, 1897-1900.

14 Y. B. Ye, K. P. S. Cheung, L. S. He and G. C. Tsui, Org. Lett., 2018, 20, 1676-1679.

15 (a) A. A. Haddach, A. Kelleman and M. V. Deaton-Rewolinski, Tetrahedron Lett., 2002, 43, 399-402; (b) A. Hfaiedh, H. Ben 
Ammar, J. F. Soule and H. Doucet, Org. Biomol. Chem., 2016, 14, 4947-4956; (c) H. Suzuki, A. Tsukuda, M. Kondo, M. Aizawa, Y. Senoo, M. Nakajima, T. Watanabe, Y. Yokoyama and Y. Murakami, Tetrahedron Lett., 1995, 36, 1671-1672.
16 X. S. Wu, Y. Zhao and H. B. Ge, J. Am. Chem. Soc., 2015, 137, 4924-4927.

17 W. Gati, F. Couty, T. Boubaker, M. M. Rammah, M. B. Rammah and G. Evano, Org. Lett., 2013, 15, 3122-3125. 18 CCDC number 1876301 (2a) $\dagger$ contains the supplementary crystallographic data for this paper. 